\section{Psychiatric assessments of patients on remand}

DeAr Sirs

I read with interest Dr Lucas's letter which described a serious problem in making psychiatric assessments of patients on remand in prison (Psychiatric Bulletin, August 1989, 13, 453-454).

As a forensic psychiatrist I often have difficulty in conducting a detailed psychiatric assessment of a patient remanded in custody. However, I generally do not encounter any problems in obtaining the depositions and other relevant information. It is usually a simple matter to telephone the prison prior to visiting the patient to ensure that the information required will be at hand. If the depositions are not immediately available, the Prison Medical Officer, or Hospital Officers, will invariably make efforts to obtain them.

In my opinion, more serious problems arise from the difficulty in obtaining skilled, on-going assessments of a patient's mental state and behaviour in prison. However, the 1983 Mental Health Act introduced new powers for the courts to remand mentally disordered defendants to hospital and such provisions allow greater flexibility in assessment and treatment. In the more difficult cases, it is often worthwhile considering using either Section 35 or Section 36, neither of which require the hospital to make any long-term commitment to the patient.

Reaside Clinic

MICHAEL BOND

Rubery, Rednal

Birmingham B45 9BE

\section{Mental handicap and child psychiatry}

DeAR SirS

The report of the working committee on the training requirements of psychiatrists serving the needs of mentally handicapped children is most timely (Psychiatric Bulletin, June 1989, 13, 326-328). Nowhere else is the overlap between mental handicap and child psychiatry more obvious than in the management of this group of patients. Yet there are not many training schemes in mental handicap which offer adequate training to senior registrars who intend to specialise in this area. The tradition of allowing senior registrars in mental handicap to work for two sessions a week of "special interest" in child psychiatry does not seem to meet the training needs. The report says that a minimum of six months full time or its equivalent in a child mental handicap setting is necessary for "Senior registrars who intend to apply for posts offering a district service in child psychiatry and posts in full age range of mental handicap". (Presumably, this refers to senior registrars in child psychiatry and not to senior registrars in mental handicap). While six months' experience in a child mental handicap setting might help, some experience in adult mental handicap should also be encouraged. This experience should be full time and at least for six months. Likewise, any senior registrar in mental handicap who wants to apply for a post specifically in child mental handicap should be encouraged to seek some full time experience in child psychiatry. This should be in addition to the required experience in child mental handicap. This will not only go some way in meeting the training requirements but also improve communication between the two specialities.

\section{University of Michigan Hospitals \\ Child and Adolescent Psychiatric Hospital \\ 1500 E Medical Center Drive \\ Ann Arbor, MI 48109-0706, USA}

\section{Lunacy and behaviour}

\section{Dear Sirs}

I enjoyed Howard's excellent contribution to the literature on the lunacy theory of behaviour (Psychiatric Bulletin, July 1989, 13, 382-383). He uses escapes from old Bedlam as his measure of this alleged effect and found no positive association with lunar phase. However, studies of attacks on nurses within psychiatric hospitals, another measure of "disruptive behaviour", indicate that most such events are diurnal, occurring when there is no moon (Fottrell, 1980; O'Shea et al, 1983). He quotes Rotton \& Kelly (1985) to illustrate that the majority of hospital-based psychiatric nurses still believe in a lunar influence. I found the exact opposite, i.e. no nurse reported the moon or its phases as a cause of difficult behaviour (O'Shea et al, 1983).

Of course, both of these points support his conclusion that the moon is an innocent observer.

Newcastle Hospital

BRIAN O'SHEA

Greystones, Co Wicklow

Ireland

\section{References}

FotTRELL, E. (1980) A study of violent behaviour among patients in psychiatric hospitals. British Journal of Psychiatry, 136, 216-221.

O'SheA, B., Mee, D., McGennis, A. \& Storey, A. (1983) Patients' violence towards psychiatric nurses. Psychiatric Nursing, 2, 15-20.

Rotron, J. \& Kelly, I. W. (1985) Much ado about the full moon: a meta-analysis of lunar lunacy research. Psychological Bulletin, 97, 286-306. 